\title{
PROTECTING THE ENVIRONMENT BY REDUCING FOOD LOSS AND WASTE ACROSS THE FOOD SUPPLY CHAIN
}

\author{
SHAHLA M. WUNDERLICH \\ Nutrition Optima LLC, USA
}

ABSTRACT

The Food and Agriculture Organization of the United Nations has reported that the estimated global food loss and waste (FLW) is significant and varies among different food products. The total loss is up to $40-50 \%$ for root crops and up to $30 \%$ for cereals. These losses happen throughout the food supply chain (FSC) including during the agricultural production, transfer, and finally during the use by consumers. Most of the food loss occurs during the initial stages of the food production while most of the waste occurs in the final stages of FSC by retailers and consumers. The high rates of FLW globally along the FSC contribute to the depletion of the natural resources and the rise in greenhouse gas emissions which ultimately impact the environment adversely. According to the 2017 Natural Resource Defense Council report in the United States (US), food and agriculture use a significant amount of natural resources such as land (half), water (67\%) and energy up to $16 \%$. The purpose of this paper is to highlight the importance of this problem and the potential impact on the natural resources which may compromise the environment and world bio-network. Although the FLW can happen in any stage of FSC, many reports suggest the first and last stages of the FSC as the most significant contributors of FLW and environmental resource depletion. It has therefore, become clear that causes of global FLW throughout the FSC could be due to many factors. Environmental implications, accessible food for all and sustainability must be considered when the issue of FLW is examined. There have been many studies which address this issue which ultimately affects both the environment and the sustainability of the food supply. The green food supply chain which is aimed at integrating environmentally friendly and sustainable food production practices is becoming a popular way to address this issue in the US. Keywords: food loss, food waste, environment, consumer, food supply chain (FSC), green food supply chain (GFSC), greenhouse gas, carbon footprint, sustainability.

\section{INTRODUCTION}

It is estimated that 1.3 billion tons or about one-third of all food produced globally is lost or wasted every year [1], [2]. Reduction of this food loss and food waste must become a priority to be able to feed the estimated global population increase to about 10 billion people in 2050 , up from current population of 7.8 billion [3]. The Food and Agriculture Organization of the United Nations released a report recently regarding food loss and waste (FLW) and indicated that this is a global issue and actions at all levels must be taken to reduce FLW [2]. The report furthermore explains that if the FLW practice continues at the current level, the consequences of it on the environment, food availability for all, and food price, to name a few, will be grave. The FAO estimated that global FLW is about $25-30 \%$ of the total available food and the report additionally indicates that the level of FLW in different parts of the world and the type of food losses are varied [2]. For example, the FLW in Japan may differ from the United States (US) and also from developing countries.

The FLW can occur in all phases of the food supply chain (FSC). Knowing this fact, current systemic practices within the FSC must change to better conserve the environment and to safeguard enough for the growing world population. All stakeholders should try to achieve a sustainable food supply for the future, via a sustainable agricultural system, food transport and preparation, and even on the consumer consumption level [4]. The first step is 
to understand where the greatest impacts on FLW can be made by exploring where and why it occurs. Then we can look at other models of success for potential solutions and effective practices that lead to reduced food loss/waste, conservation of our natural resources and achievement of a sustainable food supply for the future.

\subsection{The FSC}

The FSC refers to the processes that include delivery of food from food production sites such as farms to consumers. Fig. 1 shows a typical FSC model. During these processes, raw materials (food) are moved from suppliers to manufacturers, food industries, distributers, retailers, restaurants and finally to customers. These are the stakeholders in all phases of the FSC that can influence one another as products move down the supply chain and they are interconnected [5], [6]. At the same time, the concern for environmental protection, food accessibility, and food security is becoming increasingly essential as the world's population expands. Therefore, some food production systems are moving toward more sustainable processes that produce higher product yields and less FLW. On the other hand, consumers also must become more aware of how to reduce food waste.

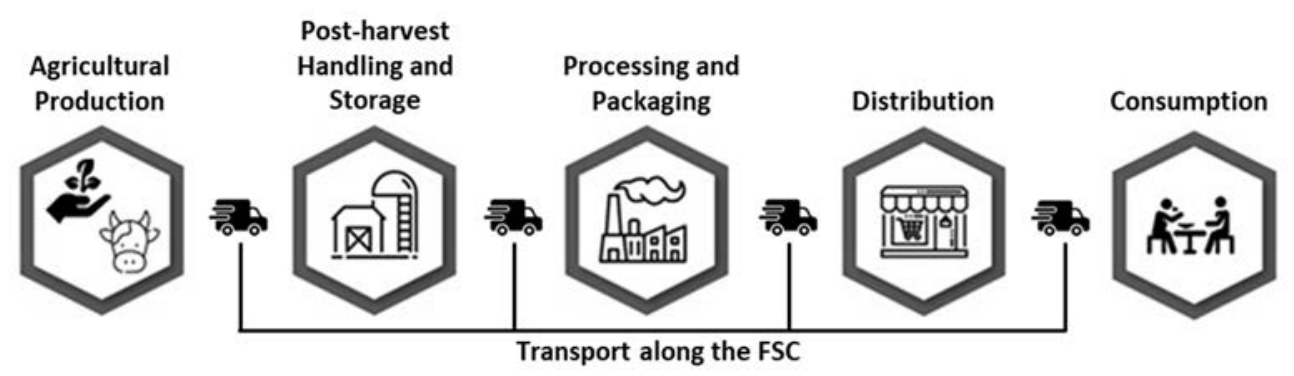

Figure 1: A typical FSC.

Therefore, to address the above concerns, the green food supply chain (GFSC) is gaining popularity in the US as it emphasizes environmentally friendly and sustainable practices. It is a concept that takes the environmental impact of the FSC into consideration. For example, "green" food companies strive to minimize pollution produced during all phases of the supply chain, including food production, transportation, and delivery to consumers. Performing Life Cycle Assessments on crops to predict sustainability and delivering quality goods to consumers are both goals of the GFSC [7]. The consumers prefer and demand the products that are produced in the GFSC model. Many factors influence consumers' food selection, ranging from taste, to nutrition, to cost. However, most recently in some countries, consumers are becoming increasingly more concerned and interested in how their food is produced, for example, sustainable agriculture verses genetically manufactured food production [5]. Consumer education on the food production system and sources of FLW will help to reduce food waste as they are not always aware of the consequences of their actions.

\section{FOOD LOSS AND WASTE}

The FSC stages involve everything from the food production and harvest on the farm (production), to transportation (handling and storage), packaging (processing and packaging), distribution (distribution and marketing), and finally to where the food product is in the hands of the consumer (consumption). Throughout this complex global system, 
millions of pounds of food are produced in order to feed the world's population but are also lost and wasted as a result of various shortcomings throughout the FSC. The definition of food losses at the production stage are the actions that occur during or immediately after harvesting on the farm and often is due to food left behind in the field. Food loss can also happen during handling and storage after food leaves the farm. Storage and transport often cause food loss due to spillage, pests, bacteria, and suboptimal storage conditions, and transporting food for long periods of time to consumers. Loss can occur during the distribution process to wholesale and retail markets. Waste at the consumption stage refers to losses in the home or business of the consumer and includes restaurants, schools, and caterers. While millions of pounds of edible food are thrown away every year throughout the supply chain, 815 million people, primarily in underdeveloped countries, are hungry and undernourished (12.9\%) [3]. In the US alone, 15.8 million households are estimated to be food insecure [8]. It is estimated that by achieving a $15 \%$ reduction in food waste, all food insecure households in the US can be fed. Furthermore, if food losses are reduced significantly it is possible that an additional 1 billion people can obtain adequate food [5], [9].

The GFSC emerged as FSC incorporate the environmentally sustainable practices into food production. Some examples of environmentally conscious processing practices include reducing the amount of pesticides used during farming in order to promote biodiversity, decreasing water usage, preventing soil erosion, and treating livestock ethically. There are companies that are using the GFSC with success and innovation. For example, one company replenishes water in water-insecure communities in order to offset the 305 billion liters of water used per year in the production of its products [5]. During the transportation process, some companies may also opt to condense shipments to reduce $\mathrm{CO}_{2}$ emissions while shipping products. From a retailing standpoint, using recyclable packaging for products would be a sustainable way to participate in the FSC. Finally, consumers may participate within the GFSC by selecting and using products that have been produced in environmentally mindful ways. For consumers, therefore, it is important to do some research so that they are knowledgeable about how their food was produced and processed within the FSC.

\subsection{FLW in developing countries}

In 2018 the United Nations reported that the hunger and undernourished rate is about $12.9 \%$ in the underdeveloped countries. Even in the US alone, 15.8 million households are estimated to be food insecure [2], [3]. It is also estimated that by reducing food waste by $15 \%$, all food insecure households in the US can be fed. Furthermore, with reduced food losses, it is possible to feed an additional 1 billion people [9]. With a steadily increasing demand for food, especially in developing countries, there is great concern regarding the ability to provide an adequate global food supply for the future population. If these wasteful practices continue, the soil, freshwater, oceans, forests and biodiversity will be in danger of destruction [2], [3].

The FLW happen more at different stages of FSC in developing countries. Food loss in developing countries is more significant at the initial phases of food production, mostly in farms and storage. Food having been left on farms after the harvest for a long period of time and in storage conditions is not optimal, for example not refrigerated, leads to food spoilage. This often occurs due to one or a combination of factors such as the financial situation, professional, educational and technical limitations. In countries like Sub-Saharan Africa and Southeast Asia, where a significant percentage of the population has limited access to enough food and they are food insecure and malnourished, the efforts on food waste reduction must 
be directed on the beginning of the FSC (harvesting and storage) where most loss occurs [3]. Hence, FLW reduction in these countries should be focused on training proper harvesting, assuring appropriate storage facilities to reduce spoilage and access to up-to-date technological tools that can help to reduce food loss.

The protection of the earth's water and soil has to become a priority, as without adequate availability of the natural resources, food production diminishes. Consequently, the ability to produce good quality food for all through environmentally responsible methods should be explored and implemented.

\subsection{FLW in developed countries}

In contrast to FLW in the developing countries, in the developed countries the food waste occurs primarily during the latter stages of the FSC, i.e.: during distribution and marketing, and consumption. Consumers and restaurants waste a significant amount of otherwise edible food. Some actions have been taken to educate and to reduce food waste at this stage of FSC by reuse, food donation to food banks, effective food labeling for expiration dates and portion control in restaurants. The thorough review of FLW in both developing countries and developed countries was published in the International Soil and Water Conservation Research Journal in 2018 [5]. A comprehensive review also has been done to highlight the importance of sustainable operations in food loss in the Belgian food processing industry. In this study the authors concluded that "human errors are responsible for most food loss" [7]. The food processing loss due to human errors has happened in $75 \%$ of participating companies which is substantial and must be addressed to correct these errors.

\section{IMPACT ON THE ENVIRONMENT}

The impact of FLW on the environment must not be overlooked, as these practices exert extensive demand on the natural resources and subsequently increase the rate of global climate change through greenhouse gas (GHG) emissions. The National Aeronautics and Space Administration (NASA) report on global temperature anomalies from 1880 to 2018 shows that the earth's temperature has risen by almost $2^{\circ} \mathrm{F}$. This is mostly contributed to human activities that produce a large amount of carbon dioxide and other GHGs that are released into the earth's atmosphere damaging its first line of protection [10]. North America is a major contributor of per capita food waste and produces about 1,900 pounds of $\mathrm{CO}_{2}$ that is responsible for approximately $2.6 \%$ of all US GHG productions. The amount of $\mathrm{CO}_{2}$ of a food production is the total amount GHG's it releases throughout its life cycle. The US is considered the second largest contributor in the world of GHG emission. This translates to the equivalent of 37 million vehicles a year [11]. FLW not only just affect and reduce the quantity of edible food available, but most importantly distress many natural resources that are required in food production for the world's growing population. Human behaviors and lifestyles, such as through food waste at the consumer stage, contribute to and increase the rate of global climate change.

\subsection{Policies to reduce FLW}

A number of initiatives are in place to reduce waste in the US. For example, in 2013, the United States Department of Agriculture (USDA) and the Environmental Protection Agency (EPA) launched the US Food Waste Challenge [12]. This challenge called on every part of the food chain: farms, processors, manufacturers, grocery stores, restaurants, universities, schools and local governments to join efforts to reduce, recover and recycle food waste. It is 
a joint effort with the goal of leading to a fundamental shift in how we think about and manage food and food waste in this country stated the USDA, Office of the Chief Economist in 2018. To bring more attention and increase public awareness about FLW, the USDA and the EPA set a national goal to cut food waste in half by 2030 which aligns with targets set by the United Nations' Sustainable Development Goals [3]. Concurrently, with these efforts, in 2015, the U.S Congress improved food donation tax incentives and expanded the incentives to businesses of all sizes to improve food recovery efforts. Following that, the food industry via the Consumer Goods Forum, a global consortium of more than 400 retailers and manufacturers, committed to halve food waste within the operations of its members by $2025[5]$.

\section{MATERIALS AND METHODS}

This paper is based on the review study process which began by identifying relevant published articles and reports of national and international government agencies to gain an understanding of the subject and scope of the FLW issue as a global concern. Furthermore, the agencies reported on specific policies and current initiatives and efforts to reduce food lass and waste which were explored. The US, governmental and private, and agencies and organizations such as USDA, EPA, NASA and United Nations agencies, the United Nations FAO websites were used to retrieve the most current information. Additionally, some reports by research groups that are committed to global sustainability such as the World Resources Institute and the Natural Resource Defense Council also were reviewed. Other online platforms, the Google Scholar, Public Health databases were also reviewed by using key words such as food loss, food waste, FSC and environmental impact among others. The systemic review of peer reviewed literature which focuses mainly on the research of FLW at the first and last stages of food consumption was conducted and published in the International Soil and Water Conservation Research for more information [5].

The FAO's definitions of food loss and food waste were used throughout this paper [1], [2]. In addition, the words sustainability and sustainable agriculture are referred to by the defining parameters of the USDA and EPA. Food loss mostly occurs during the beginning of the FSC, namely the stages of production, harvesting, handling, storage, and processing and packaging. Food waste typically occurs during the last two stages of the FSC: retail distribution, marketing, and consumption. Food waste refers to food that is discarded due to labeling, before or after its expiration date, or not used and left to spoil and then become not suitable or safe for human consumption. The retailer and consumer behaviors could be of either due to negligence or other reasons that lead to throw food away and waste food that could be used to feed people. These behaviors and actions are central issues that may limit food availability that support human needs and also reducing the future generation's food supply.

\section{RESULTS AND CONCLUSIONS}

There are many factors that contribute to the world's FLW and at the same time there are currently multiple successful campaigns and initiatives around the globe that are aiming to reduce FLW. However, there are also challenges which can only be overcome by encompassing all the stakeholders including farmers, food industries, governments, policy makers and consumers to work together. The global sustainability that will meet the increasing food demands of the world's population with the responsibility of feeding 10 billion people in the future without depleting the natural resources, poses a tremendous challenge. Implementing integrated social marketing campaigns will require massive market research, teams of professionals, marketing agencies, and specific sectors of the supply chain 
in order to be successful [13]. These are tremendous and costly undertakings. First and foremost, achievement of a sustainable food future where the FLW is reduced by $50 \%$ by 2030 will require radical change and cohesion on the fronts of policy reform. However, policy reform takes significant time and there are many hurdles to passing legislation. For example, in 2016, the US Food Date Labeling Act was presented (but not passed) to address and reduce food waste that occurs as the result of seller safety regulations and consumer confusion about the various date labeling phrases seen on food packages. This bill could aid in food recovery and redistribution efforts and reduce the likelihood of consumers tossing good food away. Food date labels present a significant challenge to supermarkets, restaurants and even food pantries that have to follow specific regulations when distributing food with past dates. Establishing a more standardized, easily understandable dating system will decrease confusion amongst consumers about whether a product is or is not still safe to eat [14].

This review paper was to address briefly the current available body of information regarding the causes of global FLW along the stages of the FSC and the possible actions required to reduce the depletion of the world natural resources. The recent FAO report indicates that "the biodiversity that is crucial for our food and agriculture is disappearing by the day" and there should be some interventions at all levels to prevent the risk to the future of the world ecosystem and biodiversity [15].

The main theme that appears throughout the review process is that the causes of FLW are complex and multifactorial. This paper justifies the need for action along the supply chain to sustain our natural resources [5], [16]. It also calls for additional research surrounding potential solutions to food loss in developing countries especially at the first stage of the FSC, production, the most resource intensive stage. Additionally, needs vary greatly dependent on region, climate, crop majority and infrastructure. Conducting needs assessments to tailor effective interventions and pilot programs to determine effectiveness is warranted. Expanding research to other developing countries in Southeast Asia is warranted as well. There are some suggested effective ways to reduce food waste such as utilizing the stockpiled food in the local government storage through food banks [17].

At the consumer end of the supply chain, especially in wealthy countries, policies and initiatives must target consumer knowledge and beliefs about the environmental impacts of wasted food and food date labels and increasing acceptability of cosmetically suboptimal foods. Changes in policy could lead to tremendous costs to finance and implement infrastructural changes that would transition to green economies which reduce carbon emissions, FLW, and reduce the depletion of our natural resources.

The most recent review paper by Nosratabadi et al. [18] describes a business model that addresses the possible changes in each stage of FSC (Fig. 2) that can be taken to alleviate some of the global food shortage in the future. The review study "reveals that solutions for improving the business model will vary based on the position of a business in the FSC" [18]. The authors recommended that to bridge the gap between food supply and food demand for the next 50 years, all stakeholders in the FSC should optimize values they are creating and delivering to their customers. The study also suggested that the strategies such as engaging the stakeholders in value creation processes and compatibility with the social and environmental factors are crucial in this process [18]. Furthermore, the Economic Research Service of the USDA released a report that explains "drivers of food loss on the farm and other pre-retail sectors, with a focus on economic incentives that underlie the way fresh foods are grown, processed, and marketed in the United States" [19]. This report mainly focuses on the perishable food such as fruits and vegetables and they are important components of a healthy diet. A published paper by authors in University of Foggia, Italy explains that the issue of reduction of FLW is a global responsibility that needs to be addressed in order to 
provide enough quality food for all. These actions will help to conserve not only environmental resources but create economic wellbeing [20]. Furthermore, the paper offers strategies to minimize FLW along the FSC. It covers different actions that have been taken in different countries to reduce FLW and to improve environmental health. Obviously, to be more effective in minimizing FLW the government policies and regulations must be also considered.

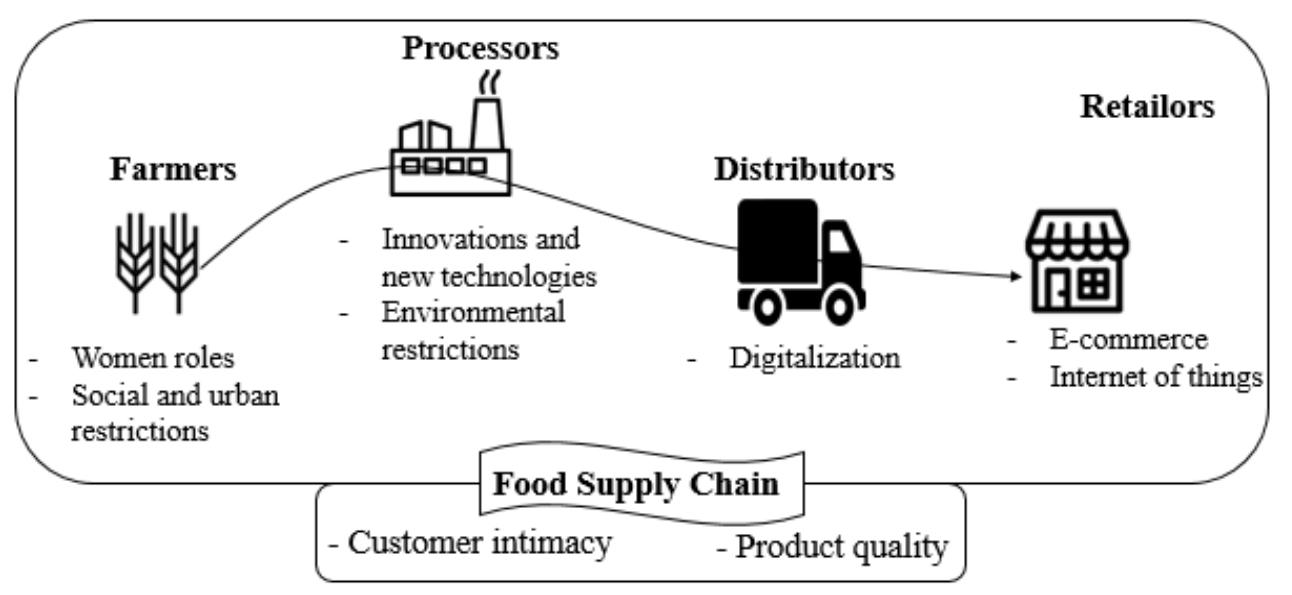

Figure 2: The business model innovation in the FSC [18].

\section{RECOMMENDATIONS}

The results are that the most recent estimates are highly variable from source to source which reflect the complexities involved with these estimates. Furthermore, there is limited availability of reliable and valid tools to assess FLW at all levels of the FSC. Although this review mainly focused on the greatest contributors of FLW: loss at the production stage and waste at the consumer stage, it is evident that to elicit significant improvements, a global approach is required. Most interventions that currently exist are in the form of social marketing campaigns that aim to increase awareness, knowledge and self-efficacy of consumers to foster food saving behavior changes. While this has proven to be somewhat effective, systematic changes that make food saving the easy and possibly only choice are necessary. This requires policy reforms and improvements in infrastructure in both developed and developing countries and introducing appropriate technology, for example providing refrigerated conditions for food storage and transport to reduce food spoilage. Novel and sustainable approaches to both food production and the environmental wellbeing must be implemented throughout the FSC. The FLW minimization can be successful when all stakeholders along the FSC collaborate and work together in a coordinated manner to implement manageable strategies in reducing FLW and safeguarding the earth's resources.

\section{ACKNOWLEDGEMENTS}

The author would like to thank Natalie Martinez and Marielle Smoller for assisting in collecting and analyzing the initial data and reviewing the literature for the previous manuscripts. 


\section{REFERENCES}

[1] Food and Agriculture Organization of the United Nations, Global Initiative on Food Loss and Waste Reduction, FAO: Rome, 2015. www.fao.org/3/a-i4068e.pdf.

[2] Food and Agriculture Organization of the United Nations, The State of Food and Agriculture, 2019. www.fao.org/state-of-food-agriculture/en/

[3] United Nations, Sustainable Development Goals, 2018. www.un.org/sustainabledevelopment/hunger/.

[4] Scholten, H., Verdouw, C.N., Beulens, A. \& van der Vorst, J.G.A.J., Defining and analyzing traceability systems in food supply chains. Advances in Food Traceability Techniques and Technologies: Improving Quality Throughout the Food Chain, eds M. Espiñeira \& F.J. Santaclara, Woodhead Publishing, pp. 9-33, 2016.

www.sciencedirect.com/topics/agricultural-and-biological-sciences/food-supplychain.

[5] Wunderlich, S.M. \& Martinez, N.M., Conserving natural resources through food loss reduction: Production and consumption stages of food supply chain. International Soil and Water Conservation Research, 6(4), pp. 331-339, 2018. https://doi.org/10.1016/j.iswcr.2018.06.002 2019.

[6] Natural Resource Defense Council, Assessing corporate performance on waste reduction: A strategic guide for investors, 2017. www.nrdc.org/sites/default/files/ corporate-performance-food-waste-reduction-ib.pdf.

[7] Wunderlich, S.M. \& Smoller, M., Consumer awareness and knowledge about food sources and possible environmental impact. International Journal of Environmental Impact, 2(1), pp. 85-96, 2019. https://doi.org/10.2495/EI-V2-N1-85-96.

[8] Hunger Notes, 2018 World hunger and poverty facts and statistics, 2018. www.worldhunger.org/world-hunger-and-poverty-facts-and-statistics/.

[9] Natural Resources Defense Council, Wasted: How America is losing up to 40 percent of its food from farm to fork to landfill, 2012. www.nrdc.org/sites/default/files/wastedfood-IP.pdf.

[10] NASA, Global Temperature Anomalies from 1880 to 2018, 2019. https://svs.gsfc.nasa.gov/4626.

[11] Friedrich, T., Timmermann, A., Tigchelaar, M., Timm, O.E. \& Ganopolski, A., Nonlinear climate sensitivity and its implications for future greenhouse warming. Science Advances, 2(11), e1501923, 2016. https://doi.org/10.1126/sciadv.1501923.

[12] US Department of Agriculture, USDA and EPA launch U.S. food waste challenge, 2013. www.usda.gov/media/press-releases/2013/06/04/usda-and-epa-launch-us-foodwaste-challenge.

[13] Pearson, D. \& Perera, A., Reducing food waste: A practitioner guide identifying requirements for an integrated social marketing communication campaign. Social Marketing Quarterly, 2018. https://doi.org/10.1177/1524500417750830.

[14] Natural Resource Defense Council, The dating game: How confusing food date labels lead to food waste in America, 2013. www.nrdc.org/sites/default/files/dating-gamereport.pdf.

[15] Food and Agriculture Organization of the United Nations (FAO), The biodiversity that is crucial for our food and agriculture is disappearing by the day, 2019. www.fao.org/news/story/en/item/1180463/icode/.

[16] Wunderlich, S.M. \& Smoller, M., Food supply chain in the United States: Potential environmental impact. WIT Transactions on Ecology and the Environment, vol. 215, WIT Press: Southampton and Boston, 2018. 
[17] Sato, M., Nakano, M. \& Wunderlich, S., Effective utilization of the stockpiled food in the local government storage through food banks in Japan: Reduction of food waste. WIT Transactions on Ecology and the Environment, vol. 215, WIT Press: Southampton and Boston, 2018.

[18] Nosratabadi, S., Mosavi, A. \& Lakner, Z., Food supply chain and business model innovation, Foods, 9, 2020. https://doi.org/10.20944/preprints202001.0125.v1

[19] USDA, Economic Research Service Bulletin No. (EIB-216), 39 pp., 2020.

[20] Adamashvilia, N., Chiaraa, F. \& Fiore, M., Food loss and waste: A global responsibility? Economia agro-alimentare/Food Economy, 21(3), pp. 825-846, 2020. https://doi.org/10.3280/ECAG2019-003014. 